\title{
Treatment of lower urinary tract dysfunction in patients with multiple sclerosis
}

\author{
Report from the Committee of the European Study Group of SUDIMS (Sexual and \\ Urological Disorders in Multiple Sclerosis) \\ Clare J Fowler, Ph E V van Kerrebroeck, Annette Nordenbo, H Van Poppel (Chairman)
} London, UK C J Fowler

Department of Urology, Radboud University Hospital, Nijmegen, The Netherlands $P$ van Kerrebroeck

Department of Neurology, Holbaek Centralsygehus, Holbaek, Denmark A Nordenbo

Department of Urology, University Hospital of the Katholieke Universiteit Leuven and National Institute Multiple Sclerosis, Melsbroek Belgium

H Van Poppel

Correspondence to: Dr Fowler, Department of Uro-Neurology, National Hospital for Neurology an Neurosurgery, Queen Square, London WCIN 3BG, UK

Received 23 September 1991 and in final revised form 16 January 1992. Accepted 30 January 1992

( $¥$ Neurol Neurosurg Psychiatry 1992;55:986-989)

In March 1991 a group of urologists and neurologists from countries within the EEC* met in Leuven, Belgium, under the auspices of the European Charcot Foundation for Multiple Sclerosis and its executive chairman, Professor Dr Otto R Hommes. This first meeting of the European Study Group on Sexual and Urological Disturbances in Multiple Sclerosis (SUDIMS) took the form of a series of short lectures and discussions on aspects of the neurology, diagnosis and treatment of bladder and sexual symptoms in MS.

One of the main points of discussion arose from a difference in opinion between those from a neurological and those from a urological background. The neurologists thought a pragmatic approach to management was often justified because the decision on whether to use intermittent self-catheterisation and treatment with oral anticholinergics could be made on the basis of measurement of the post micturition residual and the patient's symptoms. The urologists advocated thorough uro-

\begin{abstract}
Department of Uro-Neurology, National Hospital for Neurology and Neurosurgery,

Abstract

Bladder symptoms in patients with multiple sclerosis (MS) are common and usually arise as a result of spinal lesions which interrupt the neural pathways connecting the pontine micturition centre to the sacral spinal cord. Thus these symptoms are particularly likely to occur in those with lower limb neurological deficits. Fortunately bladder dysfunction in MS is rarely associated with serious upper tract disease so that the problem is usually one of symptomatic management. Lower urinary tract symptoms may be both "irritative" or "obstructive" in nature and can be explained in terms of underlying detrusor hyperreflexia and incomplete bladder emptying. Treatment is aimed at minimising both these effects. Oral anticholinergic medication can be effective in reducing detrusor hyperreflexia and intermittent catheterisation is used to reduce abnormally high post micturition residual volumes. With this simple treatment, often used in combination, many less severely affected patients with MS can gain considerable improvement in controlling urinary continence.
\end{abstract}

dynamic and urological exploration before initiation of therapy (table 1). It appears, however, that the main problem for those estimated 250000 patients in Europe with disturbances of urinary continence due to multiple sclerosis is not that investigations are inadequate or effective treatments do not exist, but that many patients with troublesome symptoms do not come under any effective management. Because of the very nature of the problem it is not possible to identify the explanation for this failure, and thus the group considered that the main difficulty was that many patients are not referred by their neurologist to anyone with interest in management of this problem. This may arise through a lack of awareness on the part of the neurologists that effective, non surgical treatments for these symptoms exist. In an attempt to rectify this deficiency it was considered worthwhile to try and promote better understanding of the possible available treatments among neurologists.

For most patients with MS and bladder dysfunction the problem is one of troublesome symptoms rather than life-threatening urological complications. Although there have been reports of serious morbidity and mortality resulting from upper renal tract disease in patients with $\mathrm{MS}^{12}$ the clinical impression is that patients with MS who develop renal failure secondary to neurogenic bladder disorders are extremely uncommon. ${ }^{34}$ This is not, however, to underestimate the impact that bladder dysfunction may have on a patient with MS: unpredictable urinary urgency can render housebound those who were otherwise coping with their disabilities, and the development of nocturnal enuresis and daytime incontinence can have a devastating effect on the patient and their family.

While the treatment of MS remains sympto-

Table 1 Responses to SUDIMS meeting questionnaire (precirculated) showing what minimal investigations each of 26 centres would recommend as investigations in a young patient with a short history of multiple sclerosis with bladder symptoms

\begin{tabular}{lc}
\hline & Centres \\
\hline 1 Urine culture, residual urine, uroflow & 8 \\
$21+$ complete urodynamics & 14 \\
$31+2+$ radiology & 3 \\
$41+2+3+$ endoscopy & 1 \\
\hline
\end{tabular}


matic, proper attention should be given to the symptoms of disordered bladder function which may be very disabling.

Neurological basis for bladder dysfunction in multiple sclerosis

Continence and normal voiding require an intact neuraxis and in particular, complete integrity of those spinal pathways which connect the pontine micturition centre to the sacral spinal cord. Although involvement of the frontal lobe centres for micturition ${ }^{5}$ or the pontine micturition centre can occur in MS, the commonest cause of disorderd bladder control in MS is spinal pathology. ${ }^{6}$ Indeed if a patient has a spinal lesion, a neurogenic voiding disorder cannot be attributed to a higher lesion.

Interruption of spinal pathways which connect the pontine micturition centre to the sacral spinal cord has two major consequences for bladder function:

1) The development of detrusor hyperreflexia. This is a neurological disorder in which the bladder no longer behaves as a compliant storage organ, expanding at a low pressure to accommodate increasing urine volumes, but instead develops spontaneous waves of contraction which the patient is unable to suppress and which are sensed as an urgent need to micturate. This disorder is thought to arise from loss of the normal inhibitory spinal pathways to the sacral parasympathetic outflow and is very common in patients with MS. Urodynamic studies in MS patients have found an incidence of this disorder in between $66 \%{ }^{7}$ and $99 \% ;^{8}$

2) The other consequence of interruption of the neurological controlling pathways of the bladder from spinal disease is incomplete bladder emptying. This may be due to poorly sustained detrusor contractions, detrusor-sphincter dyssynergia or to a combination of these problems. The sustained contraction of the detrusor smooth muscle throughout voiding requires positive neural drive from higher centres ${ }^{9-11}$ which may be lost if there is spinal disease. Detrusor-sphincter dyssynergia occurs when the reflex mechanism of normal relaxation of the bladder neck or sphincter preceding the detrusor contraction is lost and there is simultaneous contraction of sphincter mechanism and detrusor. The neural pathways which coordinate relaxation of the sphincter and contraction of the detrusor exist in the pons $^{12-15}$ and the pathways whereby they exert their effect are again, damaged by spinal disease, so that detrusor-sphincter dyssynergia is a well recognised complication of spinal cord disease. ${ }^{1316}$ Dyssynergia is more difficult to demonstrate by urodynamic study than is simple detrusor hyperreflexia, necessitating either simultaneous cystoflowmetry with sphincter EMG recording and/or voiding video cystometrogram. Estimates of the occurrence of dyssynergia in patients with MS and bladder disorders have been extremely variable, ranging from $12 \%{ }^{17}$ to $88 \%{ }^{8}$ The result, however, of poorly sustained detrusor contractions and detrusor-sphincter or detrusor bladder neck dyssynergia is incomplete bladder emptying which can be easily demonstrated by measurement of the residual volume after micturition.

The pathophysiological basis of bladder symptoms in multiple sclerosis

Symptoms of neurogenic bladder dysfunction will be all too familiar to the physician who looks after patients with MS. Urgency of micturition is the commonest complaint and often occurs together with frequency as well as nocturnal enuresis and daytime urge incontinence. But in addition to these so-called "irritative" symptoms, there may also be symptoms of "obstructed" voiding such as hesitancy, poor stream, postmicturition dribbling and incomplete emptying. The pathophysiological basis of these symptoms can be explained in terms of the known urodynamic abnormalities.

A sense of urinary urgency accompanies the involuntary contractions of the bladder smooth muscle which are a feature of detrusor hyperreflexia. Frequency likewise reflects detrusor hyperreflexia, since the uninhibited bladder commonly develops pressure rises at abnormally low filling volumes. It is a fact poorly recognised by neurologists, that incomplete bladder emptying of which the patient may be unaware, can exacerbate urinary frequency. The uninhibited bladder is likely to have an abnormally low capacity (for example, 200 $\mathrm{mls}$ ) so that if there is a persistent residual volume of about $150 \mathrm{mls}$, following excretion by the kidneys of only another $50 \mathrm{mls}$ of urine, the bladder will develop further spontaneous uninhibited contractions.

Since detrusor hyperreflexia usually occurs as a consequence of spinal involvement, spasticity and reduced lower limb mobility almost inevitably accompany bladder disorders in MS. ${ }^{6}$ This impairment of mobility means that urge incontinence presents a very real problem to many of these patients.

An interrupted urinary stream is mostly due to detrusor-urethra dyssynergia and the patient may describe how they can only empty small volumes with a poor stream that stops and starts and that they feel the need to micturate again almost immediately. Patients are often unaware of incomplete bladder emptying, although many deduce that they must have this disorder because of their need to void so soon after the last attempt. Hesitancy is probably the result of interruption of those spinal pathways which coordinate normal voluntary voiding. This may progressively worsen so that eventually patients may reach the stage at which they are quite unable to initiate voluntary micturition and void instead only when they develop an uninhibited detrusor contraction.

\section{Treatment}

Treatment of urinary symptoms can be of great benefit to patients at all stages of their disease. For patients with early MS maintenance of 
continence may be of critical importance in keeping their position at work and in society. In the late stages of the disease, achieving better continence may be the only disability that it is possible to alleviate.

Since the natural history of MS waxes and wanes, treatment should be conservative and flexible. Each treatment modality should be considered in the context of the individual patient with concern for their degree of independence, intellectual capacity, social functioning, level of sexual activity and motivation. ${ }^{\text {? }}$

Since the disorders of bladder function that occur in MS are essentially of only two types, investigations should be aimed at assessing the extent to which each of these disorders exist and treatment given accordingly, bearing in mind that incomplete emptying may exacerbate hyperreflexia. The mainstay of treatment is oral anticholinergics or antispasmodics, to lessen hyperreflexia and intermittent catheterisation to improve bladder emptying. Patients who fail to respond to this treatment regime are either those unable or unwilling to perform intermittent catheterisation or those with so severe hyperreflexia that they are unable to store significant volumes between voids. The management of these patients is difficult and often unsatisfactory since it may be necessary to resort either to surgery or putting in a longterm indwelling bladder (transurethral or suprapubic) catheter. Such problems are not discussed here. Instead, attention is focused on the treatment by medical means of the large number of patients with MS who are mildly or moderately disabled but much troubled by urinary disturbances.

\section{Treatment of detrusor hyperreflexia}

Of the many pharmacological agents that have been used to reduce bladder hyperreflexia, the most effective are those with predominantly anticholinergic properties. Propantheline bromide is the longest established anticholinergic in clinical use and has been shown in clinical trials to be effective in improving hyperreflexia. ${ }^{18}$ Imipramine, one of the tricylic antidepressants has a marked anticholinergic action which is sometimes useful in the treatment of detrusor hyperreflexia. It has, however, alpha-stimulating properties which are contra-indicated in patients with emptying problems. Both drugs are still in use but more recently musculotropic antispasmodic agents have been introduced such as flavoxate hydrochloride and oxybutinin chloride. Oxybutinin chloride is also a potent anticholinergic with a high affinity for muscarinic receptors in bladder tissue and a smooth muscle relaxant. ${ }^{19}$ Terodiline was shown to have both anticholinergic and calcium antagonistic action on detrusor muscle, ${ }^{20}$ but was recently withdrawn because serious cardiac arrhythmias were reported in a small number of elderly patients taking this medication. The use of all these drugs is limited by their anticholinergic side effects; dry mouth and constipation are the most frequent side effects but impairment of accommodation with blurred vision can occur, which must not be mistaken for deteriorating optic nerve function in MS.

All anticholinergic drugs may exacerbate the tendency of the bladder to empty incompletely and the post micturition residual volume should be checked when the patient is established on treatment.

Substantial data on the efficacy of these pharmacological agents for treatment of bladder dysfunction in MS is curiously lacking. Clinicians appear to have taken a somewhat uncritical approach to prescribing for this disorder, resulting presumably from a combination of the knowledge that an anticholinergic like drug is theoretically correct and encouraged by a good response in some individual patients. Clearly justification of these treatments is an area where further research would be worthwhile.

\section{Treatment of impaired bladder emptying}

Bladder emptying by Crédé manoeuvre or by abdominal straining is not effective in these circumstances since urethral relaxation remains a problem. Attempts to stimulate detrusor contraction by pharmacological means are largely futile since betanechol chloride is ineffective when taken orally.

Some improvement of bladder emptying can be achieved by administration of alpha-blocking agents such as phenoxybenzamine or prazosine hydrochloride but since these agents can cause a drop in blood pressure the dose should be increased cautiously. ${ }^{21}$ Striated muscle relaxants (baclofen, diazepam, dantrolene) have also been used but these may increase general fatigue and muscle weakness.

Regular mechanical bladder drainage by intermittent catheterisation is highly effective. Intermittent catheterisation was first proposed as an alternative to a long term indwelling catheter in patients who had spinal injuries. $^{2223}$ Originally described as an asepetic procedure, performed by specially trained technicians, it was then shown by Lapides to be equally safe using a clean but non-sterile technique. ${ }^{24}$ There has been surprisingly little published on the use of intermittent catheterisation in patients with MS. The largest number of such patients was reported in a study by Webb et al of 172 adults, 53 of whom had MS: ${ }^{25}$ clean intermittent self catheterisation improved control of continence in $94 \%$ and there were no serious complications.

Intermittent catheterisation can be performed by the patient or their carer 3 or 4 times in 24 hours but the exact frequency is best established by the patient, since the effectiveness of the procedure will be determined by their bladder storage capacity. The technique can be taught by a nurse who has had specialised urological training. It is obviously more difficult for women to learn the technique initially and a specially designed mirror catheter can be helpful. ${ }^{26}$ Although patients may react with revulsion at first when this form of treatment is proposed, many master the technique with adequate advice and 
Table 2 SUDIMS meeting questionnaire: first line treatment for a young patient with urgency, urge incontinence and low $(<100 \mathrm{mls})$ residual urine

\begin{tabular}{lc}
\hline & Centres \\
\hline 1 Anticholinergic, antispasmodic pharmacotherapy & 10 \\
2 Intermittent catheterisation & 7 \\
3 Alpha-blocking agents, striated muscle relaxants & 5 \\
4 Pelvic floor exercise and other & 4
\end{tabular}

Table 3 SUDIMS meeting questionnaire: first line treatment for a patient with urge incontinence and significant $(>100 \mathrm{mls}$ ) residual urine

\begin{tabular}{ll}
\hline & Centres \\
\hline 1 Intermittent catheterisation alone & 5 \\
2 Intermittent catheterisation + anticholinergics & 9 \\
3 Alpha-blocking agents alone & 2 \\
4 Alpha-blocking agents + anticholinergics & 4 \\
5 Anticholinergics alone & 2 \\
6 Other/combinations & 4 \\
\hline
\end{tabular}

training. Manual dexterity is necessary but good eyesight does not seem to be essential, if motivation is strong.

The initiation of clean intermittent catheterisation raises questions about the introduction of bacteria into the bladder causing urinary tract infection. It has been shown that more than $50 \%$ of the patients on clean intermittent catheterisation had sterile urine and of the other patients who had bacteriuria, few had other signs or symptoms of lower urinary tract infection. ${ }^{27}$ Although some authors recommend prophylactic treatment with antibiotics or antiseptic agents, ${ }^{28}$ this treatment appears to be unnecessary and possibly induces bacterial resistance. Only symptomatic bacteriuria need be treated.

Clean intermittent self catheterisation is now a well established technique and is the treatment of choice in patients with MS with disorders of bladder emptying. ${ }^{9}$ A questionnaire submitted to those participants attending the first SUDIMS meeting confirmed the key position of intermittent catheterisation (table 2 , table 3 ) in management strategies. These tables, however, also indiate a marked diversity of views. The study group has now embarked on a project to establish and agree if possible, on what are the most effective methods of management of bladder dysfunction in MS and promote their widespread use.

The contribution of the participants to the SUDIMS meeting in March 1991 in Leuven, Belgium, a European Community sponsored activity, is acknowledged. Tribute is given to Prof Dr O R Hommes for his personal efforts in promoting the European Charcot Foundation for MS Research and for the
formation of the European Study Group on Sexual and formation of the European Study Group
Urological Disorders in Multiple Sclerosis.

^Participants: H M W Anten (Sittard, The Netherlands), W Artibani (Padova, Italy), L Baert (Leuven, Belgium), L H B Bemelmans (Nijmegen, The Netherlands), C Beneton (Lyon, France), C Betts (London, UK), J L Carneiro de Moura (Lisboa, Portugal), H Carton (Leuven, Belgium), $\mathrm{H}$ de Carvalho (Lisboa, Portugal), M B D'Hooghe (Melsbroek, Belgium), C J Fowler (London, UK), R Fr Hahn (Kempfenhausen, Germany), D G Hatzichristou (Thessaloniki, Greece), The Netherlands), G Jakse (Aachen, Germany), M Lazarides
(Cornwall, UK), P Mertens (Lyon, France), A Nordenbo (Holbaek, Denmark) R Opr Pesce (Roma, Italy), T Petersen (Århus, Denmark), Dr Pinzon Pesce (Roma, Italy), Tetersen (Arhus, Denmark), Dr P Seel(Malaga, Spain), D Rohrman (Aachen, Germany), P Seeldrayers (Würzburg, Germany), R Traversa (Roma, Italy), E A Tuyn (Nijmegen, The Netherlands), C Vaney (Montana, Switserland), Ph EV van Kerrebroeck (Nijmegen, The Nether-
lands), J van Neuten (Antwerp, Belgium), H Van Poppel (Leuven, Belgium), V H Vas dos Santos (Lisbon, Portugal)

1 Damanski M, Sutcliffe-Kerr A. Paraplegia of non traumatic origin and disseminated (multiple) sclerosis: urinary complications, their nature and treatment. Acta Neurol Psychiatr Belg 1964;64:495-502.

2 Samellas W, Rubin B. Management of upper urinary tract in multiple sclerosis by means of urinary diversion to an ileal conduit. ₹ Urol 1965;93:548-52.

3 Chancellor MB, Kaplan SA, Blaivas JG. Detrusor-external spinchter dyssynergia. In: Bock $G$, Whelan $J$, eds. Neurobiology of Incontinence. Ciba Foundation Symposium. Chichéster: John Wiley 1990:195-213.

4 Leibowitz U, Kahana E, Jacobson SG, Alter M. The cause of death in Multiple Sclerosis. In: Leibowitz U, eds. Progression in multiple sclerosis: research and treatment. New York: Academic Press, 1972:196-209.

5 Andrew J, Nathan PW. Lesions of the anterior frontal lobes and disturbances of micturition and defaecation. Brain 1964;87:233-62.

6 Betts CD, D'Mellow MT, Fowler CJ. Neurological features of bladder dysfunction in multiple sclerosis. (In press).

7 Van Poppel H, Vereecken RL, Leruitte A. Neuromuscular dysfunction of the lower urinary tract in multiple sclerodysfunction of the lower urinary
sis. Paraplegia 1983;21:374-9.

8 Philp T, Read DJ, Higson RH. The urodynamic characteristics of multiple sclerosis. Brit $¥$ Urol 1981;53:672-75.

9 Blaivas JG, Holland NJ, Giesser B, Larocca N, Madonna M, Scheinberg L. Multiple sclerosis bladder. Studies and care. Ann NY Acad Sci 1984;436:328-46.

10 Bradley WE, Teague CT. Spinal cord organisation for micturition reflex afferents. Exp Neurol 1986;22:504-16.

11 Schoenberg HW, Gutrich HM. Management of vesical dysfunction in multiple sclerosis. Urology 1980; 16:444-8.

12 Barrington FJF. The effect of lesions of the hind and midbrain on micturition in the cat. Quart $\mathcal{f}$ Physiol 1925;15:82-102.

13 Blaivas JG, Barbalias GA. Detrusor-external spinchter dyssynergia in men with multiple sclerosis: an ominous urologic condition. $₹$ Urol 1984;131:91-4.

14 de Groat WC. Central neural control of the lower urinary tract. In: Bock G, Whelan J, eds. Neurobiology of Incontinence. Ciba Foundation Symposium. Chichester: John Wiley, 1990:27-56.

15 Griffiths D, Holstege G, Dalm E, de Wall H. Control and coordination of the bladder and urethral function in the braistem of the cat. Neurourol Urodyn 1990;9:63-82.

16 Blaivas JG, Sinha HP, Zayed AAH, Labib KB. Detrusorexternal spinchter dyssynergia. 7 Urol 1981;125:545-8.

17 Gonor SE, Carroll DJ, Metcalfe JB. Vesical dysfunction in multiple sclerosis. Urology 1985;25:429-31.

18 Blaivas JG, Labib KB, Michalik SJ, et al. Cystometric response to propantheline in detrusor hyperreflexia: response to propantheline in detrusor hyperre

19 Gajewski JB, Awad SA. Oxybutynin versus propantheline in patients with multiple sclerosis and detrusor hyperreflexia. F Urol 1986;135:966-8.

20 Andersson K-E. Terodiline in the treatment of urinary frequency and motor urge incontinence. Scand $\mathcal{f}$ Urol Nephrol Suppl 1984;87:13-16.

21 Vereecken RL, Van Poppel J, Boeckx G, Leruitte A. Longterm alpha-adrenergic blocking therapy in detrusor urethra dyssynergia. Eur Urol 1983;9:167-9.

22 Guttman L. Initial treatment of traumatic paraplegia. Proc Roy Soc Med 1954;47:1103-8.

23 Guttman L, Frankel H. The value of intermittent catheterisation in the early management of traumatic paraplegia isation in the early management of traumat

24 Lapides J, Diokno AC, Lowe BS, Kalish MD. Follow up of unsterile, intermittent self-catheterization. $f$ Urol unsterile, intermi

25 Webb RJ, Lawson AL, Neal DE. Glean intermittent selfcatheterisation in 172 adults. Brit $f$ Urol 1990;65:20-3.

26 Van Poppel H, Ketelaer P, Vereeecken RL. Neuro-urological problems in Multiple Sclerosis: diagnosis and treatment. In: Gonsette RE, Delmotte P, eds. Immunological and clinical aspects of multiple sclerosis. Lancaster: MTP Press, 1984:263-9.

27 Diokno A, Childs SJ. Clean intermittent catheterisation in urinary tract infection management. Inf Surg 1985; 4:185-9.

28 Smith CR, Aison MC, Scheinberg L. Symptomatic management of Multiple Sclerosis. (Eds In: McDonald WI, Silberberg DH), eds. Multiple Sclerosis. London: Butterworths, 1986:166-83. 